\section{UTILIZAÇÃO DE GEL DE GLICOSE NO TRATAMENTO DE HIPOGLICEMIA NEONATAL}

Congresso Brasileiro Online de Nutrição da Criança e do Adolescente, 2ª edição, de 27/09/2021 a 01/10/2021 ISBN dos Anais: 978-65-89908-23-4

AZEVEDO; Lara Dias de 1, JUNIOR; Raphael Del Rouo Liberatore Junior ${ }^{2}$

\section{RESUMO}

Introdução: A hipoglicemia neonatal não é um acontecimento incomum e deve ser tratada com imediatismo, já que pode causar injúria cerebral e um prejuízo irreversível no desenvolvimento neurológico a longo prazo. Um dos tratamentos para essa complicação é o gel de glicose, administrado via oral ao recém-nascido. Objetivo: $O$ presente estudo teve como objetivo testar a operacionalidade e a segurança da utilização do gel de glicose para a correção da hipoglicemia neonatal. Métodos: O projeto de pesquisa foi aprovado pelo Comitê de Ética em Pesquisa do Hospital das Clínicas da Faculdade de Medicina de Ribeirão Preto, no parecer de número 3.219.807. Foram eleitos para participar do estudo recém-nascidos a termo, nascidos no Centro Obstétrico do Hospital das Clínicas de Ribeirão Preto, com fatores de risco para hipoglicemia: pequenos para a idade gestacional, grandes para a idade gestacional e filhos de mães diabéticas (diabetes gestacional, tipo 1 ou tipo 2). Nos casos em que os bebês apresentaram hipoglicemia assintomática durante as primeiras 24 horas de vida, foi administrado o gel de glicose em suas bocas na dose de $200 \mathrm{mg}$ por quilo de peso de glicose por um profissional da saúde previamente treinado. Novas medidas de glicemia foram realizadas de 15 em 15 minutos após a ingestão do gel, até completar 1 hora $(4 \mathrm{x})$. Os recém-nascidos que apresentaram hipoglicemia sintomática não puderam fazer parte do estudo e foi seguido o protocolo do hospital. Resultados: A amostra total foi de cinco recém-nascidos. Logo após a ingestão do gel de glicose, as glicemias de todos os participantes aumentaram e não houve o desencadeamento de alterações gastrointestinais e alergias. Conclusão: Até então, o gel de glicose tem sido de fácil utilização pela equipe médica e de enfermagem e pode ser considerado como tratamento seguro da hipoglicemia neonatal. Palavras-chave: Gel de glicose. Hipoglicemia neonatal. Tratamento. Eixo temático: Doenças, agravos, alergias e intolerâncias alimentares na infância e adolescência

PALAVRAS-ChAVE: Gel de glicose, Hipoglicemia neonatal, Tratamento 